\section{BARRIERS TO THE SAFE TRANSPORT OF CHILDREN TO HOSPITAL}

doi:10.1136/injuryprev-2012-040590d.60

Maria Wilson, James Hamill. Presenting author-Julie Chambers. Starship Trauma Service, Auckland, New Zealand

Background Trauma while travelling as a passenger in a motor vehicle is a leading cause of mortality and hospitalisation for children in New Zealand. Serious trauma is often the result of poorly fitting or incorrectly used child restraints.

Aims/Objectives/Purpose The purpose of the study was to gather new information about what Starship families know about the safe use of child car restraints, what they practice and what opportunities exist for promoting child restraint use within the clinical setting.

Methods All 200 families within five wards were provided with a short, structured interview. Questions asked about usual child car restraint use, the trip to hospital and plans for the trip home. Convenience sampling was used and the sample population was compared with the total population.

Results/Outcome Most families of children younger than five attending Starship understand and are compliant with the current New Zealand Road Rule; however there is a marked drop in child restraint use after children reach five, with over half (58.8\%) of families unaware of best practice recommendations to keep children in car restraints until they reach $148 \mathrm{~cm}$ in height. Once families were offered information about best practice they were shocked they had not been doing the best for their child.

Significance/Contribution to the Field There is an opportunity for Starship to improve child restraint practice. Many families would benefit from support both with access to child restraints and with the provision of best practice information while they are attending the hospital with their child.

It has become a common practice in Lagos Metropolise and other major cities in Nigeria to see commercial vehicles and motor bikes driving on public pedestal walkways especially during rush hours when there is heavy traffic. Some motor bikes and motor vehicle drivers especially the commercial vehicle drivers drives on pedestal walkways even in the presence of law enforcement official around without any sanction, thereby forcing school children and other people walking to jump into the main road to avoid being knock down. Sometimes children walking on the pedestal walkways are knock down and are injuried.

Aims/Objectives/Purpose This study was conducted to: Analyse the impact of driving on Pedestal walkways on children safety in Nigeria; Capture children perception of their safety while walking on the pedestal walkways; Draw the attention of the government and policy makers to put in place laws, regulations and appropriate sanctions to deter motor vehicle drivers from driving on pedestal walkways; Draw the attention of the law enforcement officials to the danger that motorbikers and motor vehicles driving on the pedestal walkways pose to children and others.

Methods The study was carried out in 5 out of the 20 Local Government Areas (LGAs) in Lagos State. The study involved the documentation of accidents involving children being knock down by of motor vehicle and motorbikes on pedestal walkways for a period of 1 year from February 2010 to January 2011. The study was carried out with the aid of shop attendants that work in shops located close the pedestal walkways. The shops attendants were recruited to monitor and document incidents of motor bikes and motor vehicles driving on pedestal walkways and accidents involving children between age 1-10 years old. The second part involve using key informant interview to determine the perception of children about their safety while walking on pedestal walkway daily to and from school. All 10 children (mainly school children) were interviewed in each of the five LGAs.

Results/Outcome The results show that commercial vehicles and motor bikes drives on the pedestal walkways daily especially when there is traffic. The data gathered from the study sites revealed that an average of 50 children are knocked down within the five Local Government by motorbikes and commercial vehicles monthly while walking on pedestal walkways. So for the 12 months that the study was carried out about 600 children were knocked down by motor bikes and motor vehicles. The result of the key informant interview shows that $89.3 \%$ of the total number of children interviewed said their are not safe walking on the walkways while motor bikes and motor vehicles drive on the same pedestal walkways while $10.7 \%$ said they do not know whether they are safe walking on the pedestal walkways while motorbikes and vehicles drive on the walkways.

Significance/Contribution to the Field The study was able to monitor and document accidents that happened in the pedestal walkway involving children, capture children perception of their safety while walking on the pedestal walkways; draw the attention of the government and policy makers to put in place laws, regulations and appropriate sanctions to deter motor vehicle drivers from driving on pedestal walkways, thus improving safety for children as they walk to and fro school daily in the streets of Lagos metropolise. 